\title{
Análisis de un texto portugués sobre el Quijote: la Relaçam de tudo o que sucedeu no sítio e defensa da grande cidade de Praga
}

\author{
Aurelio Vargas Díaz-Toledo*
}

En un trabajo anterior, ${ }^{1}$ tuvimos la oportunidad de dar a conocer un texto portugués sobre una de las más destacadas batallas, por la repercusión que tuvo, que se libraron en Europa a mediados del siglo XVIII, el sitio de Praga, en cuya parte final se incluía una carta atribuida a Sancho Panza y dirigida a su amo don Quijote.

En esta ocasión, nos disponemos a presentar la primera edición moderna de este documento para poner al alcance de los investigadores una obra, cuando menos, curiosa y que ha venido a arrojar nueva luz sobre la recepción del Quijote en Portugal.

El texto completo, publicado en 1743 en la oficina lisboeta de Luiz Jozé Correa Lemos, lleva por título Relaçam de tudo o que sucedeu no sítio, e defensa da grande cidade de Praga, escrita por hum oficial militar que assistio nela, e refere com individualidade e exacçam todos os sucessos de que foi testemunha (...) com huma carta escrita sobre a mesma matéria com várias reflexoens por hum curioso. En su portada se indica que se trata de una traducción de un original impreso en español, que, a su vez, lo era de un texto francés publicado en la ciudad alemana de Francfort. Y en efecto, gracias a nuestras investigaciones, hemos podido corroborar la veracidad de este dato al localizar en distintas bibliotecas europeas las versiones anteriores del texto portugués, aunque solo de la relación del suceso y no de la misiva final, cuyo contenido será abordado más adelante.

* Universidad de Alcalá de Henares.

1. «Presencia del Quijote en Portugal: noticia de un documento inédito», en Visiones y revisiones cervantinas. Actas selectas del VII Congreso Internacional de la Asociación de Cervantistas, ed. de Christoph Strosetzki, Alcalá de Henares, Centro de Estudios Cervantinos, 2011, pp. 889-898. 
En el caso del original francés, para nuestra sorpresa, además de existir una edición publicada en 1742, en Francfort, -que no hemos logrado encontrar-, se hicieron tres más durante el mismo año en varias ciudades francesas. Al menos, así parece desprenderse de los datos bibliográficos que ofrece la Biblioteca Nacional de París con respecto a los ejemplares siguientes: Relation de ce qui s'est passé de plus intéressant à Prague (¿Nantes, A. Marie, 1742?), Relation de ce qui s'est passé de plus remarquable pendant le tems qu'a duré le blocus de l'armée française devant Prague, et du siège de la même ville, fait par l'armée autrichienne, commandée par le Grand Duc (Toulouse, Impr. de N. Caranove, 1742), y Relation du siège de Prague par un officier principal qui a été dans la ville pendant le siège ([Lille, imp. de la Vve. C.-M. Cramé, ¿1742?]). ${ }^{2}$ Dado que parte de esta información se ofrece con ciertos reparos, es posible que alguna de estas obras corresponda en realidad a la edición de Francfort. ${ }^{3}$ Solo una consulta in situ de cada uno de los documentos podría esclarecer este asunto.

Con respecto a la anónima versión al castellano, hemos tenido conocimiento de dos ediciones: una titulada Relación de el sitio de Praga, por un oficial principal que ha estado dentro de la plaza durante el sitio (Cádiz, en la imprenta Real de la Marina y Real Casa de la Contratación de D. Miguel Gómez Guiraun, en la calle de san Francisco, s.a.), ${ }^{4}$ de 1742 o 1743, que copia casi al pie de la letra la edición francesa de Lille -lo que podría inducir a creer que esta fuera, en realidad, la de Francfort-; y otra posterior, con algunas

2. De estas tres obras, solo hemos tenido acceso a la publicada en Lille, en la imprenta de la viuda de C.-M. Cramé, en 1742, en concreto, al ejemplar de la Biblioteca Nacional de Lisboa: H.G. 43//42A.

3. Además de estas obras, existe un buen número de documentos franceses que hacen alusión al sitio y defensa de la ciudad de Praga: Broglie, Victor François (Maréchal) (duc de), Campagnes de MM. les maréchaux de Broglie et de Belle-Isle en Bohème et en Bavière, les ans 1741, 1742, 1743 (Amsterdam, Marc Lichel Roy, 1742-43). 8 vols; Fragment d'une relation du siège de Prague: Rouen, Bibliothèque Jacques Villon, Col. Coquebert de Montbret, ms. 1948; Lettre d'un officier de l'armée de M. le marechal de Broglie sur le siège de Prague (1742): Paris, Archives du Ministère des Affaires Étrangères. Inventaire sommaire. Mémoires et documents Allemagne, $\mathrm{n}^{\circ}$ 94; Lettre d'un officier de l'Armée de M. le Maréchal de Broglie, contenant la relation de ce qui c'est passé à Prague, depuis le six juillet dernier jusqu'à la levée du siège (s.l., n. d.), $8^{\circ}$ : Toulouse, Bibliothèque Municipale, Rés. C XVIII 38(34) Fonds ancien; Lettre d'un officier de l'armée de M. le maréchal de Broglie, contenant la relation de ce qui s'est passé a Prague, depuis le six juillet dernier jusqu'à la levée du siège (S.1., s.a.): Paris, Bibliothèque Nationale, 8-LB38-446; FB-19693; Relation de l'ambassade et des opérations politiques et militaires du maréchal de Belle-Isle en Allemagne (janvier 1741-avril 1742): Paris, Archives du Ministère des Affaires Étrangères. Inventaire sommaire. Mémoires et documents Allemagne, $\mathrm{n}^{\circ} 37$; Relation du siège. A Prague, le 15 juillet 1742: Verdun, Bibliothèque Municipale, ms. 644 (10 hojas); Relation ou journal du siège de Prague soutenu par les maréchaux de Broglie et de Belle-Isle, comprenant les événements arrivés du 9 juillet au 23 septembre 1742: Paris, Bibliothèque de l'Arsenal, ms. 6576 (Fechado entre 26 de julio y 25 de septiembre de 1742); Routte que Mr. Le Marechal Duc de Belle Isle a tenu avec l'Armee dans la Retraite qu'il a Fait de Prague a Egra, avec Plusieurs remarques et les Endroits ou il a désrobes ses marches aux Ennemis, en xbre, 1742: Madrid, Biblioteca Nacional, MR/43/289.

4. Para la consulta de esta edición, hemos utilizado el ejemplar de la Biblioteca Nacional de España: U/10042(5). 
variantes lingüísticas y estilísticas, publicada en Madrid bajo el título Relación de un oficial principal que ha estado en Praga durante el sitio y que haviendo sabido en Dresde todo lo que el enemigo ha divulgado en este assumpto, ha querido dar al público una noticia individual y exacta de los hechos, de los que ha sido testigo ([Madrid], se hallará en la imprenta de la Gaceta, calle de Alcalá, [1751]). ${ }^{5}$ De ambas ediciones, nos interesa resaltar ahora la primera porque habría sido la utilizada por el intérprete portugués a la hora de llevar a cabo su traducción. Su fecha de publicación y la comparación línea a línea entre las dos versiones, no dejan lugar a dudas a este respecto.

Pero al margen de las versiones francesa, española y portuguesa, también existió una inglesa, cuyo modelo fue el texto francés, que llegó a contar con dos ediciones de 1743: una, sacada a la luz en la capital londinense en la imprenta de T. Cooper, con el título An exact relation of the siege of Prague by the Prince de Deux Ponts. Done from the original French, printed at Frankfort, by his Imperial Mayesty's Orders; y otra titulada A journal of the siege of the city of Prague wrote by a principal officer to one of his friends, que fue impresa en la ciudad de Dublín.

A partir de los datos anteriores, es posible afirmar, por un lado, que la relación del sitio de Praga fue escrita originalmente en francés por un autor («hum oficial militar») cuyo nombre se desconoce y que debió asistir personalmente a los hechos narrados, tal y como se dice en la portada; por otro, que se realizaron hasta cuatro ediciones del texto francés en distintas ciudades, como son Francfort, Lille, Nantes y Toulouse; y por último, que la edición de Francfort fue utilizada como base para la primera traducción castellana así como para las dos inglesas, mientras que la versión portuguesa tuvo como modelo la primera edición en español.

5. «En este caso, nos hemos valido del ejemplar de la Biblioteca Nacional de España: $2 / 66779(3)$. 


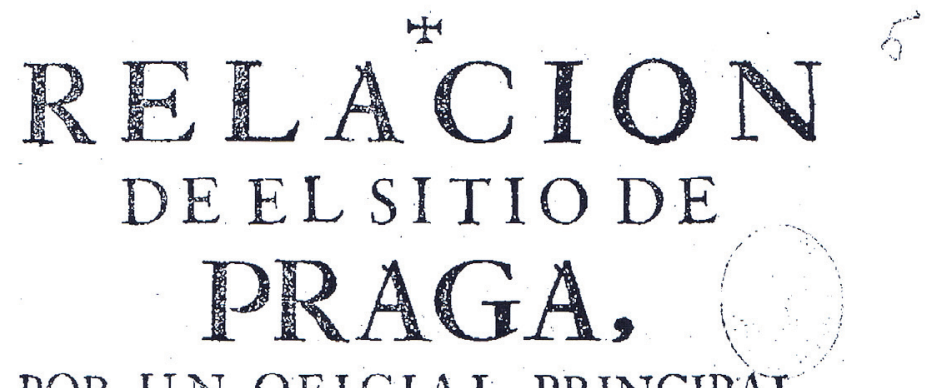

POR UN OFICIAL PRINCIPAL, que ha eftado dentro de la Plaza durante el Sitio.

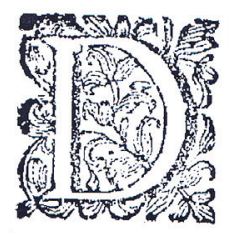

Efde el dia r 5 . de Junio, el feñor Marifcal de Belle-Isle, encargado de la defenfa de la Plaza, comenzó á hazer levantar los parapetos de los Muros, queyá eftaban cali arruinádos. Hizo poner empalizadas, y vaftiones, en las partes, que eftaban capazes de recibirlos. $Y$ aunque entonces no avia apariencia, que los Enemigos emprendieffen el Sitiai á Praga, no dexó el Marifcal de poner efta debil Plaza en eftado de defenfa, por una excefiva precaucion, que la imprndencia de los Enemigos, hizo util en lo confecutivo. El Enemigo, defpues de averfe mantenido muy largo tiempo en fuCampo, teniendo apoyada fu diestra en el alto Moldavo, leban tó el Campo el dia 26. de Julio en dos Columnas, y paffando delante del Parque, noex-

$$
\text { A ren- }
$$

Relación de el sitio de Praga (Cádiz, en la imprenta Real de la Marina y Real Casa de la Contratación de D. Miguel Gómez Guiraun, en la calle de san Francisco, s.a.) 


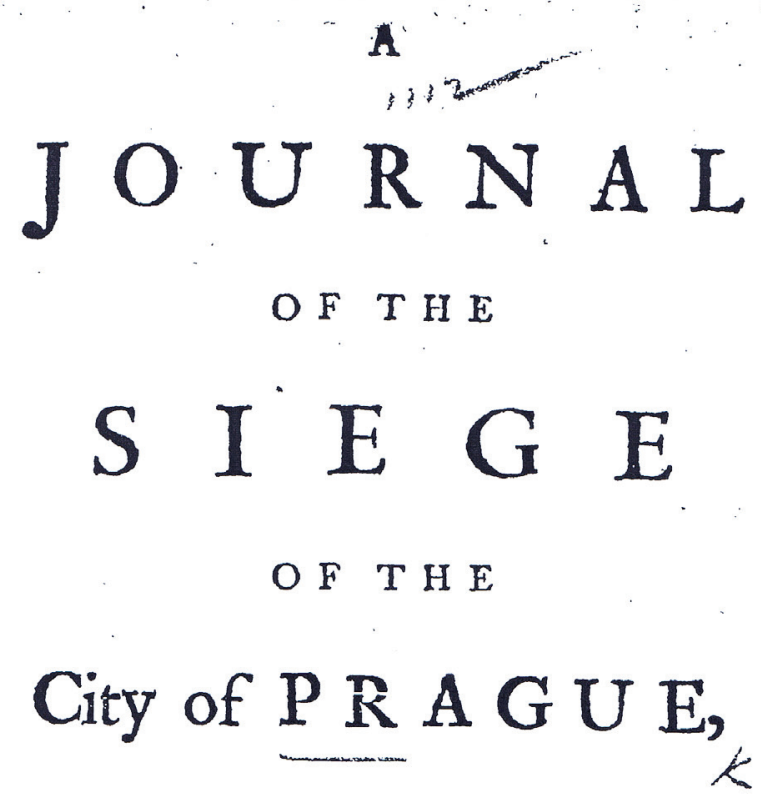

Wrote by $a$

Principal Officer to one of his Friends.

Giving an Accotnt of what happen'd during the Siege of that City, from the $13^{\text {th }}$ Day of Fuize to the a th of Sept. I 742 .

\section{$D U B L I N$ : Printed,}

And Sold by the Bookfellers, $M$ occ xu II .

A journal of the siege of the city of Prague (Dublín, 1743) 


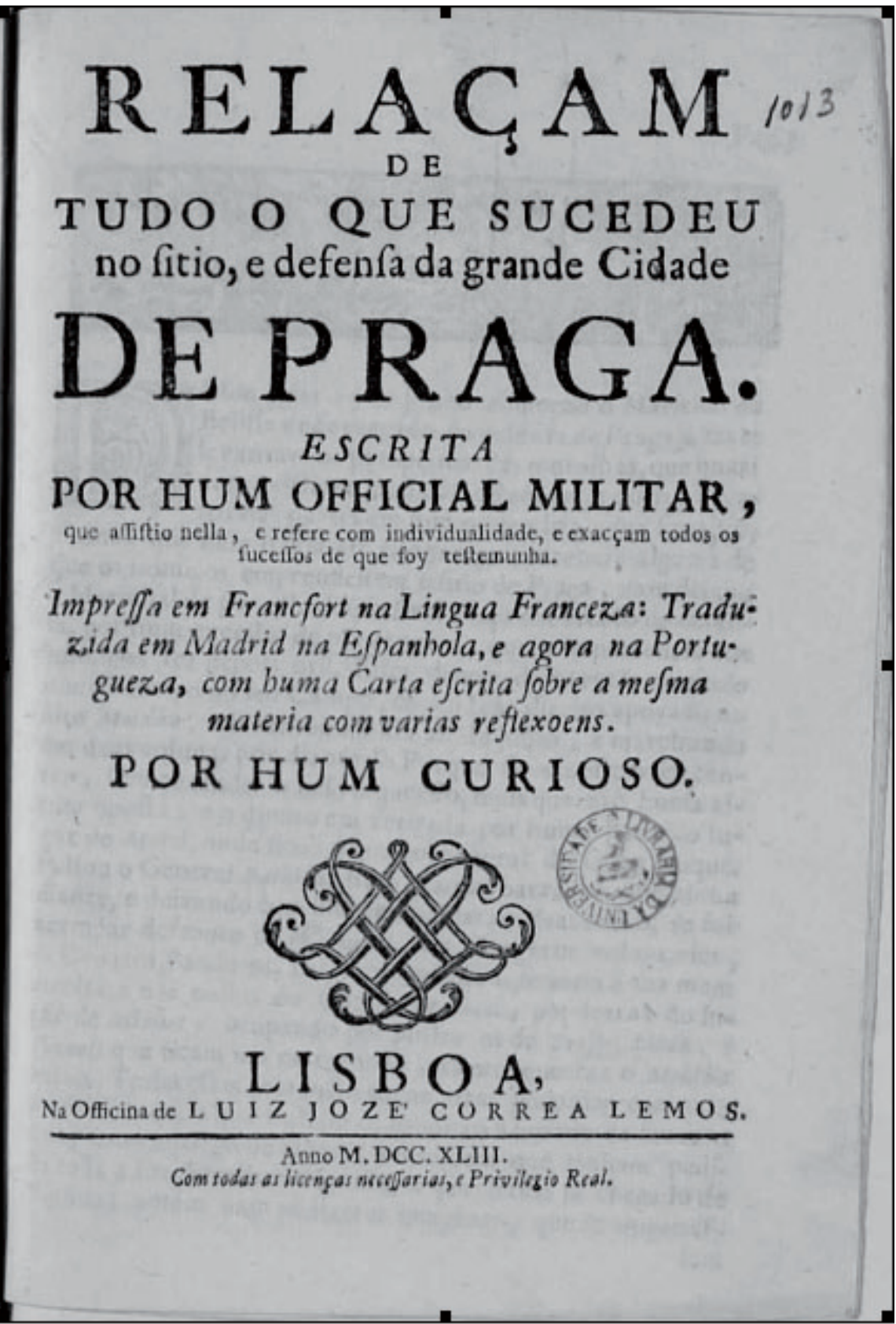

Relaçam de tudo o que sucedeu no sítio, e defensa da grande cidade de Praga (Lisboa, Jozé Correa Lemos, 1743) 
I

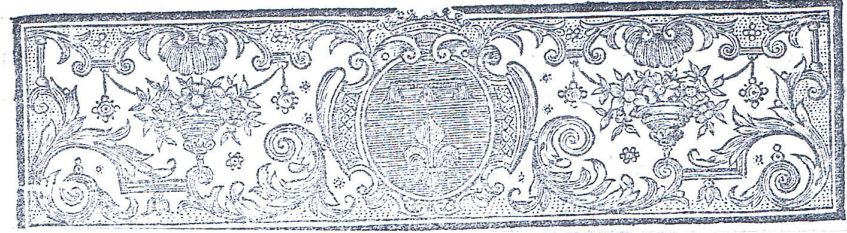

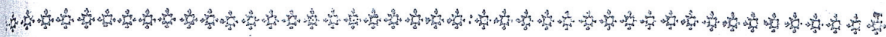

$$
\begin{gathered}
\text { IEIATION DV SIEGE DE PRAGVE, } \\
\text { par un Offucier principal, qui a été dans la Ville pendant } \\
\text { le siege. }
\end{gathered}
$$

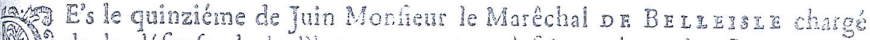
de la défenfe da la Place commenca da fare ieleyer los Tarapers des Remparts qui n'exifoient pelque plus, il y fit mexte des pahfades ge

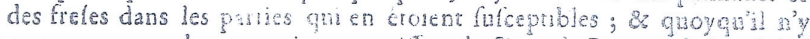
laucune aparence que les emenis enrepticut le Siege de Prague, la karkchah

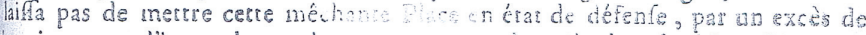
caurion, que limprudence des encus a rechu vule dans la fuire L'entema is avoir refté fort long-remps daus fon Canp, fort la droita éroit apuyés à la * Moldau, en décampa le 26. Juller fur decix Culonnes, 2 paffant devant la ic, fa gasuche ne s'érendane que jufqu'à la haurur opclée, fon cenre au Parc, adroire en retraire du côré du Village de Mothal, qui étcit le Quartier general du nd-Duc, le Gereral de Bathiany pafia un grand ravin qui écoit devant loy, \& vin uper vis-à-vis de Vifcherar, le ravin deriere lui, les Hongrois, Volontaires, Croa\& Pandoures, Talpaches \& autres camperent a ha droite derriere le Conte de - diany, a le Village de Michel, \& occuperent par des poftes ceur de Troja 8 de in \& de Porroly, quibordent le coude de la bafe Moldau. Tonres ces demon alons ne purene encore nous pertuader que les ennemis euflent envie de faire ligge, quopque nous fcufions très bien quils avoient fait venis roure leng Te artillerie de vienne, \& qu'elle broit artuce, mais nous ne pouvions pas timaginer quils s'abularent au point de comprer prendre de vive forta vue te Françoire, gui montoit encote à plus de 30000 . hommes dans ce remps

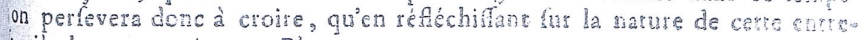
, ils la toumeroient en Blocus

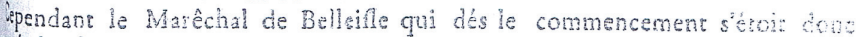
gé du foin de la Place, ne négligea aucune dass précautions qui rounrolen: ietre en érat de défenfe, a fit creufer les revres pleines des Renparts, gai vient pas affez enfonces, $a$ fit confruire des paradofes $\&$ des tepalenens is frones de Laurensberg 28 du. Carlahor; on eut la même artention fur la ide la Ville-Neuve, \& vis-à-vis de la Porre de l'Hôpiral, où le Marêtal de itle avoir déjo fair faire un chemin couverto

In soperçut le 6. Aouft que l'armée des ennemis s"étendoir par leur guche. portant fur la baffe Moldau, un peu en deca da Fillage de Roroc; o dés Gitiéme Aont ils commencerent at travailler à une batterio, for lo hanten sccupoient, vis-⿳亠丷厂svis la Chapelle de Piedmont: Ge lieus anfo nommé sa A

Relation du siège de Prague par un officier principal qui a été dans la ville pendant le siège (¿Lille, imp. de la Vve. C.-M. Cramé, ¿1742?) 
Una vez aclarada la transmisión textual, conviene abordar ahora, con el fin de tratar de comprender su contenido, la contextualización histórica de este documento, así como la identificación de los distintos personajes que se dieron cita en estos acontecimientos.

Durante los primeros años del reinado de Felipe V, en concreto en el año 1713, se firma un acuerdo conocido como la Pregmática Sanción mediante el cual se disponía la indivisibilidad de los territorios imperiales, así como el derecho de las hijas del entonces emperador del Sacro Imperio Romano Germánico, Carlos VI, a ser consideradas las legítimas y únicas sucesoras al trono.

A pesar de estas prevenciones, en 1740, a la muerte del soberano austriaco se crea una crisis sucesoria como consecuencia de los deseos imperialistas de algunas potencias europeas, que veían así la oportunidad de acabar con la hegemonía de los Habsburgo, principal obstáculo para sus propios intereses. A este respecto no hay que olvidar que el imperio austríaco no constituía una entidad nacional, sino más bien una conjunción de países unidos solo por la dinastía, lo que la convertía en un objetivo apetitoso y muy fácil de desestabilizar. Al mismo tiempo, la Casa de Austria, que poseía los Países Bajos y el Milanesado desde la Paz de Utrecht de 1714, estaba a punto de hacerse también con el ducado de Lorena mediante el enlace matrimonial entre la heredera, María Teresa de Austria, y el duque Francisco de Lorena, lo que oprimía todavía más el territorio francés.

Debido a este cúmulo de circunstancias, Francia abandera la negativa a reconocer los derechos sucesorios de la princesa María Teresa al imperio austríaco, iniciativa a la que se une, por un lado, España-que había sufrido años atrás los ataques de Carlos VI durante la Guerra de Sucesión Española-, y por otro, Federico II de Prusia, que dos años antes había iniciado la denominada Guerra de Silesia con Austria por el control de una región tan rica y estratégica, a lo que hay que sumar el hecho de que el emperador le hubiera denegado tiempo atrás la adhesión de los ducados de Berg y Cleves. De este modo, las potencias europeas se enzarzan en la primera gran guerra del siglo que da lugar a dos amplios bloques: uno formado por Prusia, Francia, España y Baviera, y otro integrado por Austria, Gran Bretaña y las Provincias Unidas.

La obra que estamos presentando se enmarca, por tanto, dentro de la que se ha venido a denominar la Guerra de Sucesión Austríaca, cuya duración total abarca del año 1740 al 1748. Durante estos conflictivos años, se publican a lo largo y ancho de la geografía europea relaciones de sucesos que describen al detalle las batallas que se libran por aquel entonces en el centro de Europa, como por ejemplo la Relación de la batalla que el día 17 de mayo de 1742 se dio en Chottositz, cerca de Czaslavv, en Bohemia, y victoria conseguida por el Rey de Prusia contra las armas austríacas, mandadas por el príncipe Carlos de Lorena (Madrid, Se hallará en la Imprenta de la Gaceta, 1742), la Relação da batalha de Dettingen, junto ao rio Meno, e victória alcançada pelo exército Inglez, e Húngaro, Comandado por S. Magestade Británica, contro o de França, às ordens do Marechal de Noailles, em 27 de Junho de 
1743 (Lisboa, Filipe de Souto-Mayor, 1743), o la Relação exacta da famosa Acçam sucedida junto a Braunau, ou cópia fiel da carta que escreveo ao muito augusta Princeza Rainha de Hungria, e Bohémia, com a notícia deste sucesso o serenissimo Principe Carlos de Lorena, Escrita do Campo de Lehendorff em 10 de Mayo 1743, de Karl Alexander Lothringen (Lisboa, Correa Lemos, 1743).

En este campo de batalla en que se convierte Europa es donde encontramos uno de los episodios más memorables de la guerra, como es el cerco a que se vio sometida la ciudad de Praga durante el verano de 1742, desde el 15 de junio hasta el 15 de septiembre. En el desarrollo del mismo los austríacos, comandados por el Gran Duque de Toscana Francisco I, pretendían acabar con el diezmado ejército del mariscal galo de Belle-Isle, Charles-Louis-Auguste Fouquet, que había sido enviado a Alemania para organizar una coalición contra la princesa María Teresa de Austria, llegando a reunir bajo sus órdenes a más de cuarenta mil hombres, la mayoría de los cuales terminará sufriendo en sus propias carnes el asedio de cerca de tres meses de duración, un asedio cuya representación se puede contemplar en el mapa incluido en el apéndice final del presente trabajo.

Este triste capítulo de la historia de Europa es el que guarda relación con el texto del que nos estamos ocupando, puesto que narra, a modo de diario y desde una perspectiva totalmente subjetiva y partidaria del bando galo, los hechos acaecidos durante el bloqueo austríaco. De este modo, se describen con gran minuciosidad los movimientos cotidianos de ambos ejércitos. Así por ejemplo, del lado de los sitiadores, se relatan sus ataques así como sus tácticas militares, destacando siempre su torpeza y su inexperiencia en las armas; mientras que por el bando de los sitiados, se habla de la construcción de murallas defensivas, de la excavación de fosos alrededor de la ciudad o de la captura de prisioneros gracias a escaramuzas periódicas que van minando la moral de los enemigos hasta conseguir el levantamiento final del sitio, mostrando en todo momento una visión demasiado idealista y con aires de superioridad por parte de las tropas dirigidas por el mariscal francés.

Descrita la defensa de la ciudad de Praga, a continuación se incluye lo que más nos interesa para el presente estudio, es decir, la carta que cierra la relación cuya autoría corresponde, según reza el encabezamiento del documento, a «hum curioso» que nada tiene que ver con el texto que le precede y que es una aportación particular del autor portugués ajena por completo a las versiones anteriores en otras lenguas. 


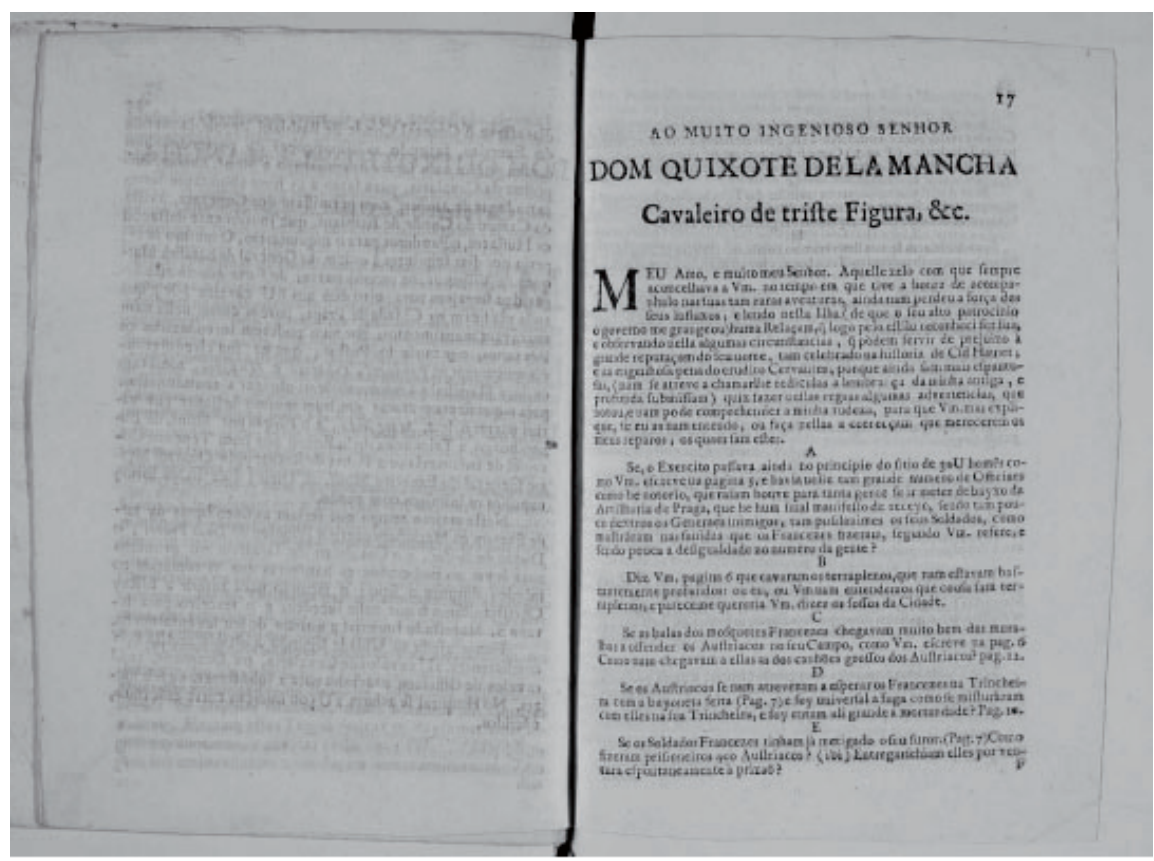

En cuanto al contenido de la misiva, trata de parafrasear la relación del cerco de Praga con reflexiones firmadas por Sancho Panza, que sería el nombre ficticio de ese "curioso" autor. Dirigidos estos comentarios a su amo don Quijote («Ao muito ingenioso senhor dom Quixote de la Mancha, Cavaleiro de Triste Figura»), a quien se atribuye, por tanto, la autoría ficticia del primer documento, su fiel escudero, observando «algumas circunstâncias que podem servir de prejuízo à grande reputaçam do seu nome», no busca sino hacerle ver, por un lado, la incoherencia de algunas partes del contenido de la relación, y por el otro, el marcado y excesivo partidismo de que hace gala.

Para ello, Sancho, que escribe desde su gobierno de la ínsula Barataria, se dedica a comentar una a una las letras que cuidadosamente se han ido colocando por orden alfabético, en mayúsculas y entre paréntesis, a lo largo de la relación, desde la $\mathrm{A}$ hasta la $\mathrm{X}$, haciendo mención cada una de ellas a aquellos aspectos más incoherentes y que más le han llamado la atención. En la mayoría de los casos, las observaciones aparecen encabezadas por un condicional y se cierran con una pregunta, sin duda para acentuar la ironía y resaltar aún más lo incongruente de lo que se glosa en cada momento. Así por ejemplo, en la letra "A", si se ensalza siempre el valor y el poder de los franceses, se pregunta el autor por qué se tienen que refugiar cobardemente dentro de la ciudad de Praga. En alguna ocasión, Sancho Panza llama la atención sobre el uso incorrecto de determinadas palabras, como sucede en la letra "B" al referirse a la expresión "cavar terraplenos", cuando en realidad se debería haber empleado el término "cavar fossos". 
Otras veces se intenta mostrar lo absurdo de algunas afirmaciones, como es el caso de las letras "C" o "H". En el primero no se explica cómo es posible que los mosquetes de los franceses alcancen a los austríacos y, por el contrario, los cañones de estos, mucho más potentes, no lleguen ni a las murallas de la ciudad; mientras que en el segundo, no entiende la gran mortandad del bando enemigo cuando se dice a las claras que no se había detenido en el combate cuerpo a cuerpo con los galos.

También se critica el contenido de aquellas afirmaciones obvias, como por ejemplo en la letra "Q", donde se dice que, si hubo varios días de calma dentro de la ciudad, eso fue porque días antes se había desencadenado un gran tumulto debido, sin duda, al ruido de las balas y las bombas de los enemigos.

Sin embargo, si hay un rasgo que predomina a lo largo de toda la carta ése es la ironía. En letras como la "E" o la "T" se hace ostentación de un fino sarcasmo que nada tiene que ver con la imagen simplona y torpe que se suele otorgar a la figura de Sancho. En esta ocasión, el fiel escudero de don Quijote demuestra no solo una inteligencia superior a la de su amo, sino también una capacidad de análisis impropia de su categoría escuderil. En la primera letra, por ejemplo, se ironiza sobre la forma en que caen prisioneros muchos de los enemigos, mientras que en el segundo caso, se muestra todavía más jocoso haciendo alusión a la posibilidad de que sus cabalgaduras fuesen alimento de los sitiados, pues se mantenían con vida gracias a la carne de los caballos.

En cuanto a las letras "Y" y "Z", que no se incluyen a lo largo del texto, son una contribución personal del anónimo autor de la carta. En ellas, manteniendo la línea irónica, llama la atención sobre dos hechos concretos: el primero tiene que ver con el autor de la defensa de la ciudad, pues no comprende que se le atribuyan todos los méritos al mariscal de Belle-Isle, cuando en realidad éste no era más que un subalterno del mariscal de Broglio, de quien no se habla casi nunca; el segundo aspecto guarda conexión con el evidente desprecio que manifiesta la relación a la hora de hablar sobre Praga, ciudad que constituía la cabeza del reino de Bohemia y que había sido siempre inexpugnable.

Antes de terminar sus observaciones, Sancho Panza ruega a su amo que le haga merced «de responder-me sobre esta matéria para saber se são bem fundados os meus reparos? E fico rogando a Deos guarde a mui engenhosa pessoa de V. M. para divertimento de todo»". Por último, la carta aparece firmada por el «Criado fiel, zeloso e obrigadíssimo criado de V. M., O Governador D. Sancho Pança», y fechada en «Dezembro 29 de 1742».

Lo interesante del texto que acabamos de presentar radica, por tanto, en la imagen concedida al escudero de don Quijote, alejada en cierta medida de la que se le ha venido otorgando durante los siglos XVII y XVIII, aquélla en la que se incide sobre su lado más ridículo, capaz de creerse a pies juntillas las disparatadas locuras de su amo, simple, torpe, incapaz de pensar por sí mismo, apegado a la realidad, glotón e interesado. Tal y como se puede contemplar en este documento, Sancho está representado de una manera distinta, inteligente, coherente en sus argumentos, serio, más cuerdo que su amo y 
con una lucidez más propia de una persona ilustrada. Por ello, en base al contenido del texto, habría que situarlo en una línea diferente a la paródica y humorística que impera durante el primer siglo y medio de recepción del Quijote tanto en España como en Portugal, una línea, al fin y al cabo, donde se manifiesta un contraste entre el mundo idealista de don Quijote y la visión más realista de Sancho Panza, con los pies en el suelo y capaz de hacer ver a su amo las incoherencias de muchos de sus argumentos, una oposición de puntos de vista que serviría de por sí para considerar el presente texto como un eslabón importante en la transmisión de la obra cervantina en Portugal durante el siglo XVIII, un período que, al contrario de lo que pudiera parecer, aún permanece muy inexplorado.

Por último, en lo que a la edición del texto portugués se refiere, hemos utilizado unos criterios relativamente conservadores. En cuanto a las grafías, hemos mantenido el uso de $v$ y $b$ según las lecturas que se documentan en el texto; las vocales nasales se marcan de acuerdo con los signos que aparecen en el impreso (-ão y $-a m$ ), aunque advirtiendo que las escasas formas en $-a \tilde{o}$

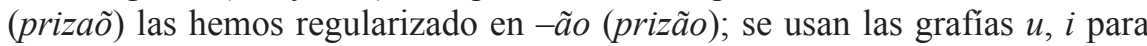
el valor vocálico (mui, baioneta), frente a $v, j$ para el consonántico. Sobre el consonantismo, se respeta el del texto base. Se respeta la presencia o ausencia en el texto de h (huma, hé). Sobre la unión y separación de palabras, hemos seguido los usos del portugués actual. Para diferenciar entre mayúsculas y minúsculas, así como para la acentuación y la puntuación, hemos tenido en consideración los criterios actuales del portugués. De igual modo, hemos desarrollado todas las abreviaturas del texto sin ninguna indicación ( $q>q u e$, pág.> página, Mons.> monsenhor, V.M.> vossa mercê) y hemos conservado sus polimorfismos y las alternancias entre vocales. Se reducen a simples las consonantes dobles (official> oficial, Vienna $>$ Viena, successo $>$ sucesso, incõmodou $>$ incomodou). Se señalan los cambios de página del impreso con el número respectivo y en exponente. Por último, hemos corregido las erratas evidentes suprimiendo lo erróneo con paréntesis angulares $(<>)$ y añadiendo lo correcto con paréntesis cuadrados ([ ]), como en el caso de empre[e]ndessem. 
Relaçam de tudo o que sucedeu no sítio e defensa da grande cidade de Praga, escrita por hum oficial militar, que assistio nela, e refere com individualidade e exacçam todos os sucessos de que foi testemunha. ${ }^{6}$

Impressa em Francfort na língua franceza, traduzida em Madrid na espanhola, e agora na portugueza.

Com huma carta escrita sobre a mesma matéria com várias reflexoens por hum curioso. ${ }^{7}$

Lisboa, na oficina de Luiz Jozé Correa Lemos, ano MDCCXLIII. Com todas as licenças necessárias e privilégio real [2 en blanco]

${ }^{[3]}$ Desde o dia 15 de Junho começou o marichal de Bellile, encarregado da defensa de Praga, a fazer levantar os parapeitos das muralhas, que quazi nam existiam já, e pôr estacadas e outros reparos nas partes em que o permitia a sua situação; e ainda que nam havia até este tempo aparência alguma de que os inimigos empre[e]ndessem o sítio de Praga, nam deixou o marichal de pôr esta despresível praça em estado de defensa, por hum excesso de prevençam, que a imprudência dos inimigos fez depois útil. Estes, depois de haver-se mantido muito tempo no seu campo, com o lado direito apoiado no alto Moldau, o levantou no dia 26 de Julho e marchando em duas colunas por diante do parque ficou neste o seu centro, sem extender o lado esquerdo, mais que até huma altura oposta, e o direito em retirada por huma parte do lugar de Motol, onde ficou o quartel general do gram-duque.

Passou o general Bathiani hum grande barranco que tinha diante, e deixando com ele defendidas as suas costas, se foi acampar defronte de Wicheral. Os húngaros voluntários, os croatos, panduros, talpaches e outros, ficaram à sua mam direita, e nas costas do conde Mariani, por detrás do lugar de Michet, ocupando os postos os de Trojie, Liben e Proneli, que ficam nas margens do recanto que faz o Moldau baixo. Todas estas demonstraçoens nam puderam, comtudo, persuadir-nos a que tinham os inimigos vontade de fazer o sítio, sem embargo de saber-se muito bem que tinham pedido toda a sua artelharia grossa, e que havia já chegado de Viena. Porém, nam podíamos imaginar que se enganassem ${ }^{[4]}$ tanto que quizessem tomar à forsa hum exército francez, que

6. «Es posible consultar una copia digitalizada de esta obra dentro de la Biblioteca digital de la Universidad de Coimbra. El ejemplar utilizado para ello corresponde a la Miscelánea 47, $\mathrm{n}^{\circ}$ 1013, procedente de la Biblioteca Geral de la Universidade de Coimbra: http://bdigital.sib. uc.pt/bg7/UCBG-misc47-nr1013/UCBG-misc47-nr1013 item1/index.html).

7. «A lo largo de nuestra investigación, hemos llegado a localizar hasta seis ejemplares de esta obrita portuguesa, repartidos en las siguientes bibliotecas: Coimbra. Biblioteca Geral da Universidade, Miscelánea 57, $\mathrm{n}^{\circ}$ 1220; Miscelánea 47, $\mathrm{n}^{\circ} 1013$ (copia digitalizada); Coimbra. Real Colégio de São Pedro, SP-G-3-20; Lisboa. Ajuda, 55-IV-47, n 12; Lisboa. Nacional, S.C. 17781; Nacional, Fundo Geral, H.G. 6627//6V (Incompleto). 
todavia passava ainda neste tempo de mais de 30U homens [A] e só havemos crido que fazendo eles reflexam sobre a qualidade da empreza, converterião o sítio em bloqueio. Porém, sem embargo de assim se entender, o marichal de Bellile, que desde o princípio tomou o seu cargo a praça, nam omitiu precauçam alguma das que a podiam pôr em estado de defensa. Fez cavar os terraplenos das muralhas, [B] que nam estavam bastantemente profundos, e construir reparos e espaldoens na fronte de Lorentsberg e de Carsthoc. O mesmo se executou diante da cidade nova, e defronte da porta do hospital, onde o marichal de Bellile tinha já mandado fazer nos princípios de Agosto huma estrada encuberta. A 6 deste próprio mez se viu que o exército dos inimigos extendia o seu lado esquerdo sobre o baixo Moldau, hum pouco mais perto do lugar de Rotoc, e desde o dia 8 começou a trabalhar em huma bataria no alto que ocupava defronte da capela de Primond, cujo sítio assim chamado hé hum grande jardim que tem diante huma fachada para a parte esquerda, defronte de Carlstor, donde começaram a tirar no dia nove pelas onze horas da manhan. Conrespondeu-lhes a cidade com todo o fogo da fachada de Carlstor, e desmontou alguns canhoens dos inimigos. Porém, a capela de Pridmont, que era muito inferior à bataria contrária, que a dominava e lhe fazia o fogo de cima, se achou muito incomodada, mas nem por isso deixou de aturá-lo e fazer todo o dia as suas descargas ou com mais ou com menos sucesso. Ao amanhecer se conduziram para a parte esquerda da caza vermelha quatro canhoes de bala de doze livras e duas de vinte e quatro, o que incomodou muito a bataria dos inimigos, que só se compunha de doze canhoens. Porém, augmen $<\mathrm{r}>[\mathrm{t}]$ aram esta no dia seguinte com muitos morteiros.

No dia dez pela manhan se retirou a artilharia da capela, onde já nam servia, e na noite de 11 para 12 de Agosto passaram os inimigos a ocupar o que chamam ${ }^{[5]}$ entrincheiramento velho, diante de Lorensberg, de sorte que desde este dia se deve fazer a conta da abertura da trincheira. A 13 pela manhan jogaram os inimigos por esta parte com duas batarias de sinco morteiros cada huma. Na noite de 14 para 15 poz o inimigo, nos altos que dominam o recanto do Moldau, batarias de canhoens carregados de metralha, que cruzavam redondamente o nosso campo. Tinha 4 canhoens no lugar de Trojie, 4 no de Liben, 3 no hospital, e 3 no sítio das cruzes. Começou o acanhoamen $<\mathrm{r}>[\mathrm{t}]$ o ao amanhecer e durou todo o dia.

Fizeram logo os nossos meter as equipagens grossas na cidade; porém, o marichal de Broglio deixou o seu campo armado como estava, retirando somente os caravineiros e duas brigadas de cavalaria, às quaes fez demarcar outro campo nas espaldas da infantaria, onde ficavão mais cobertos das balas; e sem embargo do grande fogo que os inimigos fizeram só perdemos trinta homens em todo o dia.

Ao anoitecer fez o marichal de Broglio meter parte das suas tropas na cidade, e o resto se acampou no fosso, sem haver sucedido cousa considerável, porque o inimigo se contentou em continuar as descargas da sua antiga bataria, ainda que com bastante lentidam. 
Reconheceu-se no dia 16 que tinham os inimigos passado a ocupar o posto da caza vermelha, que havíamos deixado na véspora. E a 17, ao romper do dia, se descobriu que tinhão começado a formar huma paralela, cuja parte esquerda se apoiava sobre a planície, diante da caza vermelha, e corria pela direita para o prado de santa Margarida, com 320 braças de comprimento.

Já sem embargo da mediania deste trabalho nam ficamos em dúvida de que intentavam fazer o sítio, que até entam nos parecia incrível, pois nos deram a conhecer ao mesmo tempo que tinham fixado o seu ataque por defronte do monte de São Lourenço, ali chamado Lorensberg.

A 18 se descobriu que os inimigos durante a noite tinham unido a sua nova paralela com o entrincheiramento ${ }^{[6]}$ velho, que haviam ocupado na noite de 11 para 12, o qual estava enterrado por todo a extenção da sua pertendida paralela, desde a caza vermelha até o referido entrincheiramento velho, e sem embargo de que este trabalho se fez quasi a 320 braças da muralha, se julgou que convinha fazer fogo de mosquetaria sobre os trabalhadores, aos quaes chegavão todavia mui bem as balas, [C] e também jogaram alguns canhoens pequenos. No mesmo dia fez o marichal de Bellile trabalhar em duas obras pequenas exteriores, diante do baluarte da esquerda de Lorensberg, as quaes se acabarão com muita prontidam nos dous dias seguintes, sem que o inimigo se atrevesse a interromper-nos o trabalho.

Fez o marichal de Bellile construir muitas obras exteriores, a saber, hum ninho de urraca no baluarte da explanada, à parte esquerda da porta de santa Margarida, e huma estrada encuberta com estacadas para dar comunicação à referida obra pela parte anterior. Também fez ocupar a ponte que está sobre o barranco de santa Margarida e huma ermida pequena que fica da outra parte da ponte de pedra.

Na noite de 18 para 19 propoz o Marichal de Bellile huma sahída com hum destacamento, encarregando o comandamento do lado direito ao conde de Danois, marichal de campo, o esquerdo ao duque de Biron, também marichal de campo, e o centro ao marquêz de Surgère, coronel de dragoens, o que se executou ao romper do dia. Era o destacamento composto de quatro brigadas de infantaria, a saber Navarra, Orleans, Marinha e Anjou, com 400 dragoens no centro. Sahíram as tropas com boa ordem por três diferentes portas falsas dos fossos, e marcharam com muito silêncio direitas às trincheiras dos inimigos. Porém, como estes se achavam advertidos por hum desertor do regimento de Alsácia, desde as 8 horas da noite precedente tinham reforsado a sua trincheira com tropas novas, e nos esperavam com todo o género de ventagens. Chegámos a ela hum pouco antes de amanhecer, e começaram os inimigos [7] o seu fogo assim que nos sentiram, o que continuaram todo o tempo que gastámos em marchar para abraçar toda a sua fronte, de sorte que puderam fazer contra nós muitas descargas em que nos mataram alguma gente, mas também foi tudo o que tivemos que padecer, porque tanto que os nossos soldados se viram em estado de os atacar com a baioneta feita, e sem disparar hum só tiro, se não detiveram no combate, [D] porque foi universal a fuga. E saltando a nossa gente na sua trincheira e misturando-se com eles, 
foi imediatamente grande a mortandade. Porém, mitigado o furor dos soldados [E] se fizeram perto de 400 prizioneiros assim no lado direito e esquerdo como no centro. Os três ataques se executarão em hum mesmo instante, porque em todos era igual a distância do caminho que tinhão que fazer, observando o sinal de três bombas que se arrojaram juntas da cidade como se lhes havia dado por ordem. Logo se ocuparão as tropas em destruir e cegar a trincheira dos inimigos, o que conseguiram, porque estivemos mais de duas horas senhores da direita e da esquerda sem que o inimigo, que logo se poz em marcha com toda a sua cavalaria e com o resto da sua gente de pé, se houvesse atrevido a atacar-nos, estando mais de huma hora em batalha, mas imóvel diante de nós, de sorte que houve tempo de mandarmos buscar cavalos à cidade $[\mathbf{F}]$ para levar para ela a artelharia dos inimigos. Porém, não se havendo contentado os nossos trabalhadores com encravar os morteiros e os canhoens, e havendo destruído sem ordem todos os reparos e as rodas, já quando chegarão os cavalos foi impossível levar a artelharia, e só se puderão conduzir dous canhoens pequenos de bala de seis libras, que o conde de Danois tinha mandado para a cidade no princípio do ataque com alguns trabalhadores que os levaram nos braços. Ficaram encravados na esquerda 13 morteiros e 11 canhoens, nam tendo todavia o inimigo nenhum no centro. Derramou-se e se deixou inútil toda a pólvora que tinham na trincheira. Poz-se o fogo à caza em que estava encostado o seu lado direito, ${ }^{[8]}$ que era $o$ ataque do nosso esquerdo, mandado pelo duque de Biron. Entregou-se também ao fogo a caza vermelha, mas algum tanto tarde, de sorte que tiverão tempo os inimigos de apagá-lo quando nos retirámos, o que fizemos com todo o sossego que se pode imaginar, e não somente sem que o inimigo se atrevesse a seguir-nos, mas nem ainda a entrar na sua trincheira até nos acharmos na cidade. Se crê que pôde haver ele perdido 1500 homens e se ignora o número dos feridos. Tomamos-lhe três bandeiras, grande quantidade de armas e todo o género de instromentos.

$\mathrm{Na}$ noite de 19 para 20 começou o inimigo a levantar três batarias por detrás da sua paralela, huma defronte da porta de santa Margarida, as outras duas nos seus lados direito e esquerdo, e trabalharam também em outras duas de bombas.

No mesmo dia 20 fez o marichal de Bellile continuar o considerável trabalho das minas e de outras obras exteriores, muito mais adiantadas que as que já tinha mandado fazer, chegando-as nos dias seguintes a 80 braças das trincheiras dos inimigos, de sorte que se pode dizer com verdade que havemos estado diante deles e tido por trincheira a sua pertendida paralela. Abraçavam estas obras quasi toda a fronte do lado direito dos inimigos, que era o nosso esquerdo, de modo que lhe tiraram todo o meio e toda a esperança de adiantarem as suas trincheiras, e de estabelecerem huma segunda paralela, sem haver-nos expulsado primeiro de todas estas obras que tanto se lhes avezinhavam. Porém, achavam-se as suas tropas tam amedrontadas com a primeira sahída que nam só se nam atreveram nunca atacar algumas das nossas pequenas obras, mas nem ainda a interromper-nos o trabalho que fazíamos nelas. Pelo contrário, fizemos algumas pequenas sahídas contra eles e 
foi isto bastante para entibiá-los nas que faziam. [G] Cessarão as suas batarias com as descargas depois da que fizemos no dia 19, e só tiravam com dous morteiros mui pequenos. [9] Porém, como se cria que tinham restabelecido e repairado grande parte das suas batarias, se descorreu também que haveriam levado novos canhoens; e nesta supozissam resolveram os dous marichaes fazer huma sahída no dia 22, da qual também tiveram notícia os inimigos no dia antecedente, e por consequência tempo de tomar todas as suas medidas e reforçar a sua trincheira como julgaram conveniente. Puzeram nela com efeito toda a sua infantaria, de sorte que nam ficaram mil homens para guardarem o seu campo. A sua cavalaria estava em batalha na vanguarda do campo referido, pronta a sustentar a sua infantaria, porém, nem por isso deixámos de marchar a buscá-los no dia 22 pelas 5 horas da tarde, sahíndo à sua vista pelas portas dos fossos, como nas outras vezes tínhamos feito. Compunha-se o corpo que fez esta sahída de 6 brigadas de infantaria -56 diz a tradução espanhola- a saber Auvergne, Navarra, Rei, Orlians, Rainha e Piamonte, 320 caravineiros desmontados e 400 dragoens. Mandava a vangarda da esquerda o conde de Danois, marichal de campo, e hia nela como coronel de regimento del-Rei o duque de Biron; a da direita o conde de Villemur; e o conde de Berchiny, marichal de campo, o centro.

Moveram-se as tropas todas no mesmo instante para marcharem contra o inimigo, com tanta ordem como se houvessem hido para hum exercício na paz. Marcharam unidas sem disparar hum tiro, em direitura das trincheiras dos inimigos, que pela sua parte as esperavam muito de perto, e fizeram hua descarga geral que em vez de matarem muita gente dos nossos, lhes servia de sinal de marcharem com passo mais apressado a buscá-los, e nam havendo eles tido tempo para tornarem a carregar as suas armas, nem ánimo para os esperar com a baioneta nas bocas das espingardas, se puzeram geralmente em fugida no lado direito, no esquerdo e no centro, sem que os seus oficiaes os houvessem podido deter. Porém, a confusam em que se achavam foi causa de que não pudessem sahir a tempo das suas trincheiras, ${ }^{[10]}[\mathbf{H}]$ e de que a nossa gente que se arrojou sobre eles as achassem todavia guarnecidas, e foi entam horroroza a mortandade. No primeiro furioso ímpeto dos soldados se fez toda esta execução a golpes de baioneta, e sem disparar huma só espingarda, emquanto huma partida dos mais ligeiros se empregou em seguir os fugitivos, sem podê-los conter, [I] e ainda o restante dos batalhoens se adiantou alguma coisa mais do que devia apezar dos seus oficiaes, levando toda a infantaria fugitiva até o seu campo e à paragem onde os seus esquadroens estavam formados em batalha para a sustentar. Havendo o duque de Biron conseguido que detivesse a brigada del-Rei enfurecida e empenhada em seguir os inimigos, a formou em batalha e na ordem mais bela que dispoem a arte militar, à vista da cavalaria austríaca, que se nam atreveu a abalar-se para a acometer. Porém, havendo sido ferido naquele instante, $[\mathbf{L}]$ voltou para entrar na estrada encuberta aonde recebeu segundo tiro de espingarda, $[\mathbf{M}]$ depois de haver obrado maravilhas em toda a acçam. 
Seguiram as outras brigadas o exemplo desta e havendo-se reunido, voltaram com grande ordem à trincheira dos inimigos, mas já neste tempo haviam os trabalhadores, que tinham ficado mais de hum quarto de légoa atráz, destruído as batarias, arrancado e queimado as faxinas e cegado com grande sucesso e deligência as outras obras. [N] Fizeram alto na outra parte da trincheira todas as tropas antes de torná-la a passar, até que os marichaes lhes mandaram ordem de retirar-se e de se recolherem à cidade, o que fizeram depois de haver logrado nam só executar mas exceder o que se havia ideado, porque nam só tinham arruinado todas as obras dos inimigos, mas destruído e encravado nove morteiros, que foi a única artelharia que se achou nas suas trincheiras, gastando nesta operaçam mais de huma hora. Havia-se feito juízo de que tinham posto todos os seus morteiros, e todos os seus canhoens que lhes haviam ficado nas batarias, e foi este hum dos principaes [11] objectos com que se fez esta sahída. Hé certo que se houveram podido levar para a cidade todos os seus canhoens sem excepçam e os houvéramos dezenganado da sua empreza, tirando-lhes todos os meios de a seguir, porém, ao menos se pode dizer que esta segunda acabou de arruinar e pôr em consternaçam a sua infantaria, que depois deste sucesso se nam atreveu a esperar mais os nossos nas pequenas sahídas que depois fizeram. [0]

Nam tememos que se nos note por exageraçam dizer que pereceram dos inimigos nesta sahída mais de $3 \mathrm{U}$ sem contar os feridos nem 300 prizioneiros, entre os quaes foi hum o general de batalha Monti, engenheiro, e muitos oficiaes. Perderam também duas bandeiras. Da nossa parte houve 300 homens mortos e feridos, a maior parte ao entrar da porta de santa Margarida, [P] e pelo fogo da sua trincheira, na qual os haviam feito entrar por força quando por ordem dos marichaes a abandonou a nossa gente para se recolher à cidade.

A 24 pediram os inimigos huma suspensam de armas para se retirarem os mortos de huma e outra parte, o que os marichaes lhes concederam, e depois da grande sahída de 22 até 29 se ocuparam unicamente os inimigos em aperfeiçoar os seus reductos e as suas trincheiras. Da nossa parte só houve algumas pequenas sahídas, que todas se lograram matando-lhes bastante gente e interrompendo-lhes continuamente o seu trabalho. Nam disparou o inimigo mais canham nem morteiro, e até o dia 29 se nam atreveo a levar morteiros nem canhoens para a trincheira com o receio de que nos apoderássemos deles, porque tal era a consternaçam em que os tinham posto as nossas sahídas.

Por sete ou oito dias houve na cidade de Praga hum grande silêncio e hum total socego no povo, [Q] porque o modo com que o proseguiam os inimigos nada parecia menos do que hum sítio. Em fim, havendo eles empregado 8 dias inteiros em fortificar as suas trincheiras com reductos que lhes custaram imenso trabalho, se resolveram a levar os seus ${ }^{[12]}$ canhoens e a montá-los nas batarias, havendo feito outras novas no centro e agmentado as dos lados, de modo que no dia 29 começaram a fazer com grande fúria as descargas de 39 canhoens e 24 morteiros. Conrespondeu-se da nossa parte com o fogo da artelharia bastantemente vivo. Porém, nam era isto o em que mais nós confiávamos para defender a cidade de Praga, mas nas nossas sahídas, que resol- 
vemos reiterar com quatro ou cinco brigadas, como as precedentes, quando os inimigos chegassem à segunda paralela, que hé onde os aguardávamos; e entretanto se continuaram as sahídas pequenas sempre com o mesmo sucesso, esperando que os inimigos sahíssem da sua primeira paralela para formarem a segunda, o que todavia se nam atreveram a executar, contentando-se de fazer com a sua artelharia hum horrorozo fogo contra as nossas defensas e arrojar huma quantidade prodigiosa de bombas nas muralhas e na cidade.

Três dias havia que o fogo continuava com a mesma violência quando o general conde de Konigsegg mandou hum trombeta ao marichal de Bellile propondo-lhe huma conferência, o que se admitiu para o dia 31 de Agosto. Porém, como o conde de Konigsegg nam fez mais que renovar as proposiçoens que se havião desprezado dous mezes antes em outra semelhante conferência, [R] foi esta última mui curta e se retiraram sem efeito.

Começou o inimigo de novo a disparar com mais fúria do que antes a sua artelharia, derigindo o seu fogo contra os baluartes, que estam aos dous lados da porta de santa Margarida, os quaes pertendia bater em brexa. Porém, facilmente se pode julgar que efeito poderia fazer semelhante acanhoamento na distância de 400 braças. [S] Durou o fogo com a mesma violência até o levantamento do sítio, havendo mal tratado apenas o pano da escarpa. Reconheceu o inimigo que nunca lograria abrir brexa de tão longe e que assim era precizo chegar para mais perto as suas batarias, pelo que resolveo dar princípio à paralela do seu lado esquerdo na noite ${ }^{[13]}$ de dous para três de Setembro, com algumas 200 braças de trabalho, e na noute de três para quatro, a começaram também pelo lado direito com 70 braças, levando o desígnio de aproveitar-se do barranco que ficava junto ao centro para unir os princípios das paralelas, o que se conheceu logo, perturbando-os no seu trabalho com pequenas sahídas de dez granadeiros somente, [T] que não deixaram de atrazá-lo muito.

$\mathrm{Na}$ noite de 4 para 5 se fez huma sahída de 7 companhias de granadeiros sobre toda a frontaria do seu novo trabalho, os quaes alimparão absolutamente a trincheira e matarão muita gente. Fez o marichal de Bellile avançar dous canhoens pequenos de artelharia, e alguns mosquetes da muralha para o remate do ramo direito de Laurentsberg, que em francêz se chamam pot-à-moineau, e hé hum baluarte pequeno separado por hum fosso, de que se usa quando os baluartes estam mui distantes; e como este posto nam distava mais que sinco braças da primeira paralela dos inimigos penetravão a segunda e todo o barranco, de sorte que se nam atreviam a trabalhar nela de dia, e de noite lhes matávamos muita gente nas trincheiras com as nossas sahídas.

$\mathrm{Na}$ noite de sinco para seis, mandaram os marichaes fazer huma sahída de 12 companhias todas de granadeiros contra o novo trabalho dos inimigos, quatro sobre o lado esquerdo, duas pelo centro, e seis sobre o lado direito da antiga paralela, e teve o mesmo bom sucesso, e ainda maior que as precedentes, sem embargo de haverem os inimigos posto no centro alguns batalhoens para receberem a nossa gente; porém, os granadeiros os puzeram em desordem na sua mesma trincheira, na qual entraram de mistura com eles, [S] e além da grande mortandade fizeram mais de 40 prizioneiros, entrando 5 oficiaes 
neste número. Nas noites seguintes até a de 10 para 11, sem faltar huma, se repetiram estas pequenas sahídas, e sempre com toda a felicidade, sem que [14] o inimigo se possa vangloriar de haver rechassado alguma por pequena que seja, [U] e de nenhuma voltamos sem fazer prizioneiros e matar 300 para 400 pessoas.

Desde o dia 7 não disparava já com acerto a sua artelharia. A maior parte das suas balas ou cahiam na cidade ou passavam por cima dela. As peças disparavam indirectamente para todas as partes; porém, continuaram em trabalhar na segunda paralela que tinham começado a 10 .

A 11 sahíam as suas balas e as suas bombas com menos tino e só usavam de 20 canhoens, e como se estivessem de ánimo de antes arruinar ou queimar a cidade do que continuar o sítio, arrojavam quanto mais longe podião, não só as balas mas fogos de artefício. Em fim, ao anoitecer se começou a observar hum grande movimento no seu exército e se viu muito bem que começavam a retirar a sua artelharia, o que executaram efectivamente na maior parte da noite de 11 para 12, e na de 12 para 13 levaram o resto, abandonando pelas três horas da manhan a sua trincheira, na qual deixaram quantidade de bombas, carregadas todas de fogos de artefício.

$\mathrm{Na}$ noite de 13 para 14 pegaram os inimigos fogo ao seu campo e se puseram em marcha em duas colunas, pelo caminho de Beraun, sem dúvida com o temor de que os seguíssemos se marchassem de dia, o que se houvera podido executar efectivamente se se houvesse querido remontar a cavalaria e os dragoens com os mil cavalos que ainda ficam em poder dos oficiaes, particularmente dos de infanteria, que trocaram os seus por outros melhores da cavalaria, ao tempo que os mandavam matar.

Deixaram os inimigos ao redor de Praga quando se retiraram 6 ou 7U, homens de tropas ligeiras, a maior parte húngaros voluntários ou panduros, com dous regimentos velhos de hússares somente, todos à ordem do general Festetiz. Fizeram estas tropas retirar os paisanos duas léguas em contorno e guardar todas as entradas e caminhos para nos embarassarem a conduçam dos mantiment $<\mathrm{a}>[\mathrm{o}] \mathrm{s}$. Três ${ }^{[15]}$ dias esteve o general conde de Bathiani depois da partida do exército fazendo as disposiçoens do pertendido bloqueio; porém, não serviu de embaraço a monsenhor Bureau, inspector da cavalaria, para fazer a 15 hum abundante forrejo no lugar de Miobet, com permissam dos generaes, à vista do campo do conde de Bathiani que inutilmente destacou os hússares e panduros para o inquietarem. $\mathrm{O}$ mesmo se repetiu nos dias seguintes à ordem do general de batalha marquêz de Villemur na própria parte, de sorte que só este lugar deu forrajens para oito dias aos $8 \mathrm{U}$ cavalos [X] que todavia ficam na cidade de Praga. Porém, como nela nam entravam mantimentos, por nam poderem introduzi-los os paizanos, por causa dos postos que na sua circunferência ocupavam os panduros, croatos e hússares, tomaram os dous marichaes a resolução de os obrigar a abandoná-los, para o que fizeram atacar em hum mesmo instante por várias partes o de santa Margarida e o parque por monsenhor de Luxemburgo, a trincheira de São Rocop por hum tenente coronel de infanteria, e a ponte de Rostoc pelo quartel mestre general 
do exército monsenhor de Their, e de todos foram expulsos os inimigos com perda.

Neste mesmo tempo, que seriam as sinco horas da tarde, fizeram os marichaes partir o príncipe de Duas Pontes, o duque de Brisac e o cavaleiro de Grostein: o primeiro, para levar ao Emperador as bandeiras que se tomaram ao inimigo durante o sítio; o segundo, para referir a el-Rei Cristianíssimo o que nele sucedeu; e o terceiro, para levar a Sua Magestade Imperial a notícia do seu levantamento.

Ficam ainda na cidade, segundo a última revista, 25U combatentes, $2 \mathrm{U}$ cavalos de cavalaria ou dragoens, $10 \mathrm{U}$ cavalos de oficiaes e farinha para a subsistência de seis mezes. No hospital se acham 2U 500 homens entre enfermos e feridos. [16 en blanco]

\section{${ }^{[17]}$ Ao muito ingenioso senhor dom Quixote de la Mancha, Cavaleiro de Triste Figura, \&c.}

Meu amo e muito meu senhor, aquele zelo com que sempre aconcelhava a vossa mercê no tempo em que tive honra de acompanhá-lo nas suas tam raras aventuras, ainda nam perdeu a força dos seus influxos, e lendo nesta ilha -de que o seu alto patrocínio o governo me grangeou- huma relaçam, que logo pelo estilo reconheci ser sua, e observando nela algumas circunstâncias que podem servir de prejuízo à grande reputaçam do seu nome, tam celebrado na história de Cid Hamet e na engenhosa pena do erudito Cervantes, porque ainda sam mais espantosas -nam se atreve a chamar-lhe redículas a lembrança da minha antiga e profunda submissam- quiz fazer nestas regras algumas advertências que notou e nam pôde comprehender a minha rudeza, para que vossa mercê mas explique, se eu as nam entendo, ou faça nelas a correcçam que merecerem os meus reparos, os quaes sam estes:

\section{A}

Se o exército passava ainda no princípio do sítio de $30 \mathrm{U}$ homens, como vossa mercê escreve na página 5 , e havia nele tam grande número de oficiaes como hé notório, que rasam houve para tanta gente se ir meter debaixo da artilharia de Praga, que hé hum sinal manifesto de receio, sendo tam pouco dextros os generaes inimigos, tam pusilânimes os seus soldados, como mostraram nas sahídas que os francezes fizeram, segundo vossa mercê refere, e sendo pouca a desigualdade no número da gente?

\section{B}

Diz vossa mercê, página 6, que cavaram os terraplenos, que nam estavam bastantemente profundos. Ou eu ou vossa mercê nam entendemos que cousa sam terraplenos e parece-me quereria vossa mercê dizer os fossos da cidade. 
C

Se as balas dos mosquetes francezes chegavam muito bem das muralhas a ofender os austríacos no seu campo, como vossa mercê escreve na página 6 , como nam chegavam a elas as dos canhões grossos dos austríacos? Página 12.

\section{D}

Se os austríacos se nam atreveram a esperar os francezes na trincheira com a baioneta feita (página 7) e foi universal a fuga, como se misturaram com eles na sua trincheira e foi entam ali grande a mortandade? Página 10.

$\mathbf{E}$

Se os soldados francezes tinham já metigado o seu furor (página 7), como fizeram prisioneiros 400 austríacos? (ibi) Entregar-se-hiam eles por ventura espontaneamente à prizão?

${ }^{[18]} \mathbf{F}$

Se os sitiados na sahída que fizeram da prevençam de mandar buscar à cidade cavalos para conduzirem a ela a artelharia que tinham os sitiantes na sua trincheira (página 7), como se esqueceram de ordenar aos soldados nam cometessem a desordem de quebrar as carretas e encravar as peças?

G

Se os austríacos esfriaram no trabalho das trincheiras e batarias com as pequenas sahídas que os francezes fizeram da praça (página 8), como as acharam restabalecidas e reparadas em grande parte? Página 9.

$\mathbf{H}$

Se os austríacos se nam detiveram no combate (página 10), como se misturaram com os francezes na trincheira e foi ali horrorosa a mortandade?

\section{I}

Como se admira vossa mercê de que os francezes naõ pudessem conter os austríacos, quereria vossa mercê que eles sofressem a pé firme os seus golpes? Se vossa mercê dissera que os seus oficiaes os nam puderam conter na sua fuga seria huma expressam natural.

$\mathbf{L}$

Se o inimigo estava tam imóvel que o duque de Biron pôde à sua vista pôr em batalha a brigada d'el-Rei, a qual, enfurecida, tinha chegado até aos seus esquadroens que estavam formados em batalha (página 10), quem feriu este duque na estrada encuberta, como vossa mercê assegura?

\section{M} tiro?

Se os inimigos o nam seguiram (página 10), quem deu ao duque o segundo 
$\mathbf{N}$

Se os trabalhadores tinham arruinado todas as obras dos sitiantes e queimado as suas faxinas (página 10), qual era a trincheira em que os seus generaes os fizeram entrar por força? Página 11.

\section{$\mathbf{O}$}

Se depois desta sahída se nam atreveram os austríacos a esperar os sitiados nas pequenas (página 10), parece por consequência que os esperavam nas antecedentes, porque esta cláusula o faz evidente.

\section{$\mathbf{P}$}

Se a cavalaria ficou imóvel e a infanteria consternada (página 11), como a maior parte dos mortos e feridos foi à entrada da porta de santa Margarida? (página 11) Repare, senhor dom Quixote, que sam mui maliciosos os austríacos e poderam dizer que se matavam os francezes huns aos outros sobre quem se havia de meter primeiro na cidade, por se livrarem dos seus golpes.

Q

Se na cidade houve oito dias hum grande silêncio e huma profunda tranquilidade (página 1) emquanto os austríacos refaziam as suas batarias, segue-se que houve tempo em que havia tumultos e se ouviam clamores, e isto era sem dúvida que procedia das balas e das bombas que via cair o povo.

$\mathbf{R}$

Diz vossa mercê que se nam admitiram as prepostas que fizera o conde de Konigsegg, porque eram as mesmas que se tinha $<a>m$ desprezado dous mezes [19] antes; porém, isto encontra a notícia certa de haver sido o marichal de Bellile quem fez propor, e o conde de Konigsegg o despresador, por sinal que se admirou todo o campo austríaco de ver o seu trombeta coberto de galões de ouro desde a cabeça até os pés.

$\mathbf{S}$

Se as balas cahíam na cidade ou passaram por sima dela (página 14), como nam chegavam por distantes a fazer brecha nos seus muros? (página 12).

\section{$\mathbf{T}$}

Se só com as saídas de dez granadeiros perturbavam o trabalho dos austríacos (página 13), se quando sahíam corpos grandes punham em fugida todas as suas tropas (página 13), como nam sahía todo o seu exército a obrigá-los a levantar o sítio? Ah, senhor dom Quixote!, se os sitiados sofriam o cerco só por gosto de comer carne de cavalo, ponha vossa mercê em seguro o seu Rocinante, que eu já desde agora quero pôr em salvo o meu polino. 
$\mathbf{U}$

Diz também que se nam podem os austríacos vangloriar de haverem nunca rechassado nenhuma das suas sahídas por pequena que fosse (página 14). Lembre-se vossa mercê que sahíram relaçoens que referem que na de 19 de Agosto, que foi de $6 \mathrm{U}$ homens, se retiraram carregados até a cidade, que na de 22 , em que sahiu por comandante o mesmo marichal de Bellile, na sua própria presença foram os francezes expulsos do Forte Sueco, e sendo os austríacos, que ali se achavam, metade menos que os seus contrários, os rechassaram até os fossos de Praga, e o regimento de Sirmay os carregou até a borda do fosso, e que em todas as que fizeram no mez de Setembro, em todas foram rechassados com perda. E se estavam tam bem com as partidas pequenas, com huma grande poderiam obrar proesas e fazer levantar vergonhosamente o sítio aos austríacos. Página 14.

$\mathbf{X}$

Diz mais (página 14), que quando o exército austríaco sahiu do campo, o podiam os sitiados seguir, sendo de dia, se houvessem querido remontar a cavalaria sobre o pé de mil cavalos que havia em poder dos oficiaes. Os austríacos partiram no dia 14, e logo no dia 15 apareceram na cidade $8 \mathrm{U}$ cavalos, como vossa mercê diz na página 15 , para desfrutar as abundantes forrajes do lugar de Meibet; e o torna a confirmar dizendo que segundo a última revista ficaram ainda na praça $25 \mathrm{U}$ combatentes, $2 \mathrm{U}$ cavalos de tropas, e $10 \mathrm{U}$ de oficiaes. Quem tanto se equivoca, nam acredita muito o que assegura, mas se havia tantos cavalos, donde lhes veio este socorro tam de repente? Fala vossa mercê com desprezo no valor dos austríacos, fugindo a cada sahída dos sitiados, consternados sempre com o medo dos seus destrossos, e parecera-me que antes vossa mercê realsasse mais o seu esforço, por acreditar melhor o que apadrinha, porque, se vencer hum homem valeroso hé mui estimável glória, o fugir de hum fraco hé huma injúria ignominiosa. Que dirá o mundo todo que ler esta relaçam sabendo que os sitiados lhes tinham fugido do campo de Frauenberg para Wodnian, de Wodnian para Piseck e daqui para Praga, deixando aqui e ali os almazeins e equipajes pela percipitaçam com que fugiam e sabendo que ainda os buscavam, se fortificaram debaixo da artelharia da mesma cidade onde, nam se dando ainda por seguros, se recolheram nela?

${ }^{[20]} \mathbf{Y}$

Também me parece digno de nota que vossa mercê faça toda a defença dos sitiados acçam do marichal de Bellile, sabendo todos que era ele subalterno de Broglio, nam falando nunca nele, se nam quando diz (página 6) que retirara a sua gente do fogo dos austríacos e quando as meteu na cidade. Se eu nam conhecera a vossa mercê havia de supor que o autor desta relaçam era hum dos 17 secretários do senhor Bellile. 
$\mathbf{Z}$

Chama vossa mercê desprezível praça a cidade de Praga, e não se lembra que fizeram tanto empenho para a tomar por ser a cabeça de todo o reino de Bohémia, e que para a ganhar fizerão a francezes hum ataque falso, as tropas de Saxónia dous verdadeiros, hum pela cidade nova, outro pela porta Carolina, e o conde Maurício da outra parte do Moldau, que contenderão mais de $30 \mathrm{U}$ homens francezes, bávaros e saxónios contra $2 \mathrm{U} 700$ e que, se o conde Maurício nam entrasse enganosamente por huma parte deserta, experimentaria a mesma resistência que experimentou o conde de Cosel na porta Carolina.

Quizera vossa mercê fazer-me a mercê de responder-me sobre esta matéria para saber se são bem fundados os meus reparos? E fico rogando a Deos guarde a mui engenhosa pessoa de vossa mercê para divertimento de todos.

Ilha Baratária, e de Dezembro 29 de 1742, criado fiel, zeloso e obrigadíssimo criado de vossa mercê, o Governador dom Sancho Pança

Brevemente se dará ao público o gosto de ver outra relaçam mais ampla dos sucessos de Bohémia.

\section{Fuentes textuales}

A journal of the siege of the city of Prague wrote by a principal officer to one of his friends (Dublin, printed and sold by the booksellers, 1743).

A prospect of the city of Prague with the several batteries and fortifications and the disposition of the Austrian and French Armies taken from an original Drawing upon the spot by one of the head Engineers now in the service of her Majesty the Queen of Hungary (London, Published and sold by T. Hugginson, 1742) (copia digital en: http://imageserver.mzk.cz/ mzk03/001/033/815/2619267488).

An exact relation of the siege of Prague by the Prince de Deux Ponts. Done from the original French, printed at Frankfort, by his Imperial Mayesty's Orders (London, printed for T. Cooper, 1743).

Broglie, Victor François (Maréchal) (duc de), Campagnes de MM. les maréchaux de Broglie et de Belle-Isle en Bohème et en Bavière, les ans 1741, 1742, 1743 (Amsterdam, Marc Lichel Roy, 1742-43). 8 vols.

Cartas del conde de Konigsegg (1742). Lisboa. Biblioteca Nacional, Mss. 22, no 32-33.

Fragment d'une relation du siège de Prague. Rouen, Bibliothèque Jacques Villon, Col. Coquebert de Montbret, ms. 1948. 
Historia del emperador Carlos VI y de las reboluciones que sucedieron en el Imperio...de la Casa de Austria, trad. de Jacinto de Lisasueta, Madrid, Juan de Sanz Martín, 1741-42. 2 vols.

Lettre d'un officier de l'armée de M. le marechal de Broglie sur le siège de Prague (1742). Ejemplar : Paris, Archives du Ministère des Affaires Étrangères. Inventaire sommaire. Mémoires et documents Allemagne, no 94.

Lettre d'un officier de l'Armée de M. le Maréchal de Broglie, contenant la relation de ce qui c'est passé à Prague, depuis le six juillet dernier jusqu'à la levée du siège (s.1., n. d.), $8^{\circ}$. Toulouse, Bibliothèque Municipale, Rés. C XVIII 38(34) Fonds ancien.

Lettre d'un officier de l'armée de M. le maréchal de Broglie, contenant la relation de ce qui s'est passé a Prague, depuis le six juillet dernier jusqu'à la levée du siège (S.1., s.a.). Paris, Bibliothèque Nationale, 8-LB38-446; FB19693.

Plan de l'attaque, et de la Defense de la Ville de Prague en 1742, levée par Du Mony?, 1742. Madrid, Biblioteca Nacional, MR/43/294.

Relaçam de tudo o que sucedeu no sítio, e defensa da grande cidade de Praga escrita por hum oficial militar, que assistio nela, e refere com individualidade e exacçam todos os sucessos de que foi testemunha. Impressa em Francfort na lingua franceza, traduzida em Madrid na espanhola, e agora na portugueza, com huma carta escrita sobre a mesma matéria com várias reflexõens por hum curioso (Lisboa, na Oficina de Luiz Jozé Correa Lemos, 1743).

Relação da batalha de Dettingen, junto ao rio Meno, e victória alcançada pelo exército Inglez, e Húngaro, Comandado por S. Magestade Británica, contro o de França, às ordens do Marechal de Noailles, em 27 de Junho de 1743 (Lisboa, Filipe de Souto-Mayor, 1743).

Relação exacta da famosa Acçam sucedida junto a Braunau, ou cópia fiel da carta que escreveo ao muito augusta Princeza Rainha de Hungria, e Bohémia, com a notícia deste sucesso o serenissimo Principe Carlos de Lorena, Escrita do Campo de Lehendorff em 10 de Mayo 1743, de Karl Alexander Lothringen (Lisboa, Correa Lemos, 1743).

Relación de el sitio de Praga, por un oficial principal que ha estado dentro de la plaza durante el sitio (Cádiz, en la imprenta Real de la Marina y Real Casa de la Contratación de D. Miguel Gómez Guiraun, en la calle de san Francisco [entre 1740-1749]). Madrid, Biblioteca Nacional, U/10042(5).

Relación de la batalla que el día 17 de mayo de 1742 se dio en Chottositz, cerca de Czaslavv, en Bohemia, y victoria conseguida por el Rey de Prusia contra las armas austríacas, mandadas por el príncipe Carlos de Lorena (Madrid, Se hallará en la Imprenta de la Gaceta, 1742).

Relación de un oficial principal que ha estado en Praga durante el sitio y que haviendo sabido en Dresde todo lo que el enemigo ha divulgado en este assumpto, ha querido dar al público una noticia individual y exacta de los hechos, de los que ha sido testigo ([Madrid], se hallará en la imprenta de la Gaceta, calle de Alcalá, [1751]). Madrid, Biblioteca Nacional, 2/66779(3). 
Relation de ce qui s'est passé de plus intéressant à Prague [Nantes, A. Marie, 1742], $4^{\circ}, 4 \mathrm{pp}$.

Relation de ce qui s'est passé de plus remarquable pendant le tems qu'a duré le blocus de l'armée française devant Prague, et du siège de la même ville, fait par l'armée autrichienne, commandée par le Grand Duc (Toulouse, Impr. de N. Caranove, 1742). Toulouse, Bibliothèque Municipale, Rés. C XVIII 38(33) Fonds ancien 2.

Relation de l'ambassade et des opérations politiques et militaires du maréchal de Belle-Isle en Allemagne (janvier 1741-avril 1742). París, Archives du Ministère des Affaires Étrangères. Inventaire sommaire. Mémoires et documents Allemagne, $\mathrm{n}^{\mathrm{o}} 37$.

Relation du siège de Prague par les Autrichiens en 1742, Chartres, Garnier, 1863 , in- $8^{\circ}, 20 \mathrm{pp}$.

Relation du siège de Prague par un officier principal qui a été dans la ville pendant le siège (Lille, imp. de la Vve. C.-M. Cramé, 1742?). Ejemplares conservados: Paris, Bibliothèque Nationale, Rés. F. 211 (31); Lille, Bibliothèque Municipale, 31302; 32454; Lisboa, Biblioteca Nacional, H.G. 43//42A; Perugia, Biblioteca Augusta, I-3-251F-(18).

Relation du siège. A Prague, le 15 juillet 1742. Verdun, Bibliothèque Municipale, ms. 644 (10 hojas).

Relation ou journal du siège de Prague soutenu par les maréchaux de Broglie et de Belle-Isle, comprenant les événements arrivés du 9 juillet au 23 septembre 1742. Paris, Bibliothèque de l'Arsenal, ms. 6576 (Fechado entre 26 de julio y 25 de septiembre de 1742).

Routte que Mr. Le Marechal Duc de Belle Isle a tenu avec l'Armee dans la Retraite qu'il a Fait de Prague a Egra, avec Plusieurs remarques et les Endroits ou il a désrobes ses marches aux Ennemis, en xbre, 1742. Madrid, Biblioteca Nacional, MR/43/289.

\section{Obras generales}

Abreu, Maria Fernanda de, Cervantes no Romantismo português. Cavaleiros andantes, manuscritos encontrados e gargalhadas moralíssimas, Dissertação de doutoramento em Literaturas Românicas Comparadas, apresentada à Universidade Nova de Lisboa em 1992. Editada en Lisboa, Editorial Estampa, 1997.

Abreu, Maria Fernanda de, «Cervantes en Portugal», en Alicia Villar Lecumberri (ed.), Peregrinamente peregrinos. Actas del V Congreso Internacional de la Asociación de Cervantistas. Lisboa, Fundação Calouste Gulbenkian 1-5 septiembre 2003, Asociación de Cervantistas, 2004. I, pp. 3-15.

Almeida, M. Lopes: Catálogo da colecção de miscelâneas (Vols. I a LXXV), Coimbra, Coimbra Editora, 1967.

Ares Montes, José, "Cervantes en la literatura portuguesa del siglo XVII», en Anales Cervantinos, II (1952), pp. 193-230.

Ares Montes, José, «Don Quijote en el teatro portugués del siglo XVIII», en Anales Cervantinos, III (1953), pp. 349-352. 
Bacallar y Sanna San Felipe, Vicente (marqués de José del Campo Raso), Comentarios de la guerra de España e historia de su rey Felipe V, el Animoso, ed. Carlos Seco Serrano, Madrid, Atlas, 1957.

Barroso, Carlos, Cervantes en Portugal, Curiosidade Literária, Lisboa, 1872.

Campo Raso, Joseph del, Continuación a los comentarios del marqués de S. Felipe desde el año 1733, Madrid, Imprenta Real, 1793. Tomo $4^{\circ}$.

Figueiredo, Fidelino de, «O Thema do Quijote na Literatura Portuguesa do Século XVIII», en Revista de Filología Española, Madrid, Centro de Estudios Históricos, Tomo VII, 1920, pp. 47-56.

Figueiredo, Fidelino de, «O Thema do Quijote na Literatura Portuguesa do Século XIX», en Revista de Filología Española, Madrid, Centro de Estudios Históricos, Tomo VIII, 1921, pp. 161-169.

Peixoto, Jorge, «Bibliografia das edições e traduções do D. Quixote publicadas em Portugal», en Boletim Internacional de Bibliografia Luso-Brasileira, Lisboa, Fundação Calouste Gulbenkian, Vol. 2, pp. 597-622.

Teijeiro Fuentes, Miguel Ángel, «Portugal en la vida y obra de Cervantes», en Revista de Estudios Extremeños, Vol. 62 (2006), pp. 683-700.

Toribio Medina, José y Joaquim de Montezuma de Carvalho, Cervantes em Portugal, Lisboa, Nova Vega, 2005.

Vargas Díaz-Toledo, Aurelio, «Presencia del Quijote en Portugal: noticia de un documento inédito», en Visiones y revisiones cervantinas. Actas del VII Congreso Internacional de la Asociación de Cervantistas, ed. de Christoph Strosetzki, Alcalá de Henares, Centro de Estudios Cervantinos, 2011, pp. 889-898.

Vargas Díaz-Toledo, Aurelio y Alexia DOTRAS BRAVO, «Nueva edición del Cartel de desafio y protestación cavalleresca de Don Quixote de la Mancha, Cavallero de la Triste Figura, en defensión de sus castellanos (Lisboa, Domingos Lopes, 1642)», en Suplemento de la Revista Colóquio/Letras, 178 (2011), pp. 77-86. 


\section{Apéndice 8}

Routte que Mr. Le Marechal Duc de Belle Isle a tenu avec l'Armee dans la Retraite qu'il a Fait de Prague a Egra, avec Plusieurs remarques et les Endroits ou il a désrobes ses marches aux Ennemis, en xbre, 1742. Madrid, Biblioteca Nacional, MR/43/289.

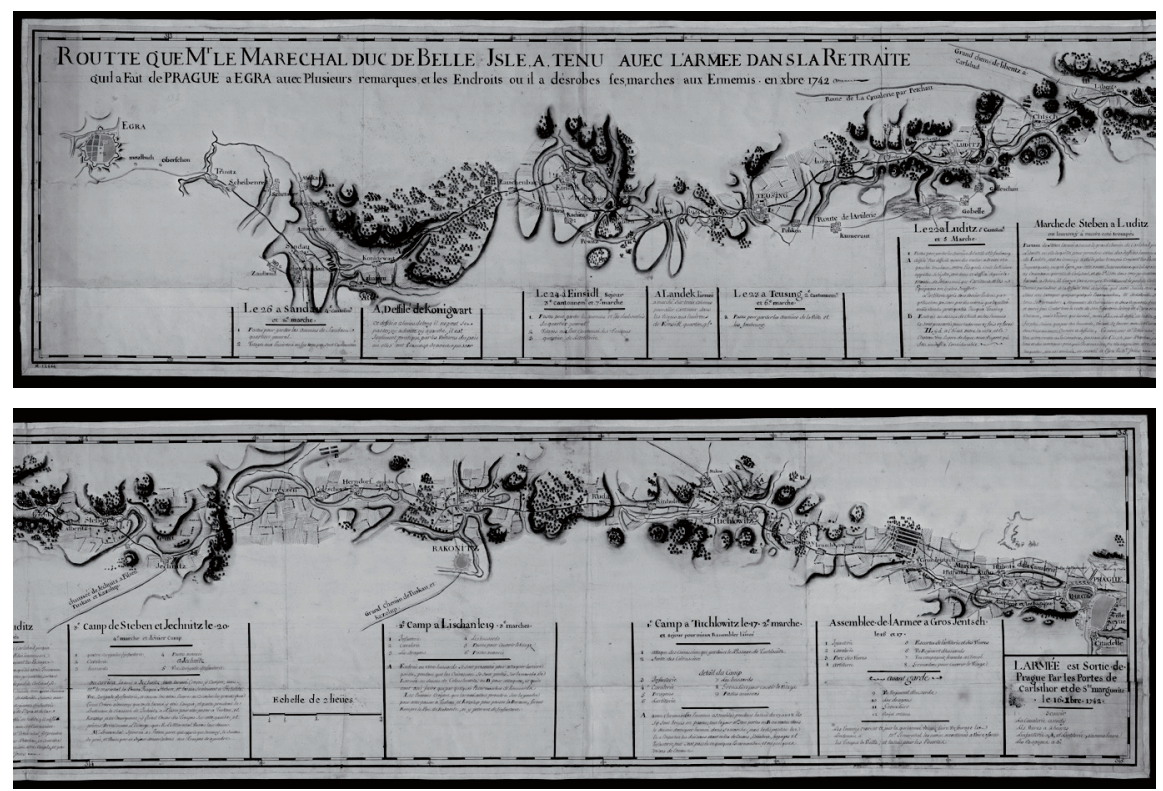

8. «Otra imagen interesante sobre la defensa de Praga se puede ver en el mapa titulado A prospect of the city of Prague with the several batteries and fortifications and the disposition of the Austrian and French Armies taken from an original Drawing upon the spot by one of the head Engineers now in the service of her Majesty the Queen of Hungary (London, Published and sold by T. Hugginson, 1742), del que existe una copia digitalizada en el siguiente enlace: http://imageserver.mzk.cz/mzk03/001/033/815/2619267488. 
Recibido: 27 de abril de 2012

Aceptado: 18 de junio de 2012

\title{
Resumen
}

En el presente trabajo se edita por primera vez un texto portugués de 1743 conocido como Relaçam de tudo o que sucedeu no sítio e defensa da grande cidade de Praga, en cuya parte final se incluye una pequeña carta firmada ficticiamente por Sancho Panza y dirigida a su amo don Quijote de la Mancha. Además de ofrecer un breve estudio sobre la transmisión textual del primer documento, se lleva a cabo un análisis de la misiva que la sitúa en una nueva línea de la recepción del Quijote distinta de las conocidas actualmente en tierras portuguesas.

Palabras clave: Quijote. Recepción en Portugal. Edición de texto.

\begin{abstract}
This work publishes for the first time a Portuguese text of 1743 known as Relaçam de tudo o que sucedeu no sítio e defensa da grande cidade de Praga, in which final section is includes a small fictitious letter signed by Sancho Panza and destined for master Don Quixote of La Mancha.

Besides offering a brief study of the textual transmission of the first document is carried out an analysis of the letter which places it in a new line of receipt of the Quixote other than those currently known in Portugal.
\end{abstract}

Keywords: Quixote. Reception in Portugal. Edition of the text.

Título en inglés: Title: Analysis of a Portuguese text on Don Quixote: the Relaçam de tudo o que sucedeu no sítio e defensa da grande cidade de Praga 